\title{
Bilateral Third Nerve Paralysis as a Manifestation of Guillain-Barré Syndrome
}

\author{
Sepideh Paybast, Omid Hesami, Mohsen Koosha*
}

Department of Neurology, Imam-Hossein Hospital, Shahid-Beheshti University of Medical Science, Tehran, Iran

\begin{abstract}
Gullian-Barré syndrome (GBS) is an acute autoimmune polyradiculoneuropathy with many variants and distinct presentations. Although cranial neuropathy is a common feature in GBS, third nerve palsy is a rare presentation. Herein, we describe a case of GBS patient who has presented by acute flaccid quadriparesis coexisting bilateral third nerve palsy. We tried to highlight the importance of other cranial nerve involvement in the natural history of GBS.

Keywords: Gullian-Barré syndrome; Third nerve palsy; Polyneuropathy.
\end{abstract}

\author{
*Correspondence to \\ Mohsen Koosha, MD, \\ Department of Neurology, \\ Imam-Hossein Hospital, \\ Shahid-Beheshti University of \\ Medical Science, Tehran, Iran; \\ Email: \\ mohsenkoosha63@gmail.com
}

Published online 19 June 2018

Citation: Paybast S, Hesami O, Koosha M. Bilateral third nerve paralysis as a manifestation of Guillain-Barré syndrome. Int Clin Neurosci J. 2018;5(2):78-80. doi:10.15171/icnj.2018.15

\section{Introduction}

Gullian-Barré syndrome (GBS) is an acute immunemediated polyradiculoneuropathy which often occurs a few days to weeks after an antecedent infection, trauma, surgery or vaccination. The incidence of typical GBS varies worldwide between 0.6 and 4 cases per 100000 annually. ${ }^{1-3}$ The main clinical presentations are rapidly progressive, areflexic flaccid paralysis involving proximal and distal muscles relatively symmetrical. Cranial neuropathy in GBS is common ranging from $50 \%$ to $75 \%$ with the most common pattern as bilateral facial palsy. ${ }^{3-6}$ Although ophtalmoparesis as sixth nerve palsy is mostly seen in Miller-Fisher variant, there are very few instances in the literature where bilateral third nerve palsy in GBS has been reported. St Louis and Jacobson reported a 77 years old man who had been diagnosed with GBS that developed unilateral third nerve palsy, facial and bulbar paralysis over hospitalization. ${ }^{7}$ Similarly, in 2008 Burina et al reported a 61 years old female with GBS (acute motor and sensory axonal neuropathy subtype) associated with bilateral oculomotor nerve palsy. ${ }^{8}$

Herein, we describe a case of GBS patient who has presented by acute flaccid quadriparesis coexisting bilateral third nerve palsy.

\section{Case Presentation}

Patient's Demographics, History, Physical Examination A 68-year-old man presented in referral for a month history of progressive ascending paraparesthesia following the surgical laminectomy a month before admission accompanied by muscle weakness in the same fashion. In a way that he has been unable to stand over 2 weeks with a progression to the upper limbs by the third week. The patient had a history of bilateral painless ptosis since 7 days which had been completed over this time. There was no history suggestive of bulbar, facial or sphincter involvement.

His medical history except for previous surgery was otherwise unremarkable.

On examination, the patient was alert and conscious. His vital signs were normal. Cranial nerve examination revealed mild bilateral peripheral facial palsy, lack of upward movement of both eyelids. In a passive eyelid opening, the eyes were diverted both outwards and downwards with restricted ocular movements except in lateral eye movement (Figure 1). The pupils were both mydriatic and non-reactive to light (complete bilateral third nerve palsy). Rest of the cranial nerve examination was normal. Motor system revealed hypotonia in all four limbs. Power muscle was grade $4 / 5$ in upper limbs and $2 / 5$ in lower limbs with predominantly proximal weakness. Deep tendon reflexes were absent in lower limbs and hypoactive in upper limbs. Sensory system indicated decreased all sensation modality in distal limbs. There was no sensory level. Cerebellar examination was
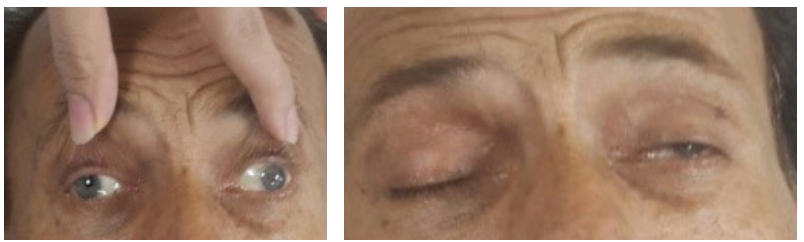

Figure 1. Work-up and treatment

(C) 2018 The Author(s). This is an open access article distributed under the terms of the Creative Commons Attribution License (http:// creativecommons.org/licenses/by/4.0/), which permits unrestricted use, distribution, and reproduction in any medium, provided the original work is properly cited. 
normal according to patient's cooperation. Other system examination revealed no abnormality.

Routine blood chemistry tests were normal. The patient had been under lumbar puncture which showed opening cerebrospinal fluid (CSF) pressure $9 \mathrm{CmH} 2 \mathrm{o}$ and normal glucose cell with a protein 304 . CSF viral serology and gram stain and culture were negative.

On the second day of admission, nerve conduction study (NCS) (Tables 1 and 2) was performed which yielded considerable reduction in the compound motor action potentials (CMAP) with prolonged distal latency and reduced conduction velocity of median, ulnar, peroneal and tibial nerves in a range of demyelinating process. The ulnar and median Sensory nerve action potential (SNAP) were absent, however the sural SNAP was spare. Electromyography (EMG) showed reduced recruitment in all limbs accompanied by evidence of fibrillation, positive sharp waves and polyphasia in lower limbs muscles. The findings were suggestive of subacute axonaldemyelinationg polyradiculoneuropathy.

Intravenous immunoglobulin (IVIG, $25 \mathrm{~g}$ IV daily for 5 days) was instituted and a partial improvement observed in the lower limbs muscle power to $3 / 5$. In addition the patient was able to open his eyes mildly.

\section{Discussion}

The third nerve palsy is an uncommon presentation in GBS. There are a few reports of third nerve palsy associated with GBS in the literature. The first studies in this area were carried out by Ropper et al who reported 8 patients with severe ptosis in GBS. ${ }^{9}$ Similarly, St Louis and Jacobson reported a case of classic GBS who developed cranial neuropathy including of bilateral third nerve palsy. ${ }^{7}$ Burina et al reported a 61 years old female with GBS associated with bilateral oculomotor nerve palsy. ${ }^{8}$ Imam et al reported a case of Isolated Bilateral Ptosis as a variant of GBS over Miller Fisher syndrome. ${ }^{10}$

A case described, the presence of albuminocytological dissociation in the CSF, the NCS-EMG pattern especially the sural sparing feature and clinical course were in favor of GBS.

\section{Conclusion}

GBS is a heterogeneous disease with distinctive characteristics. The most common manifestation is the acute inflammatory demyelinating polyneuropathy.

More than half of the patients might develop cranial nerve involvement, especially facial palsy. However,

The third nerve palsy is an uncommon presentation in GBS. The present report indicates the diverse clinical spectrum of GBS.

Conflict of Interest Disclosures

The authors declare that they have no conflict of interests.

\section{Ethical Statement}

Informed consent was obtained by the patient for publication of this case report.

\section{References}

1. Mazumdar J, Bhattacharya T, Sing CK, Nandi M. Bilateral Ptosis with Hypoglossal Nerve Palsy in Guillain-Barre Syndrome: A Rare Presentation. J Neurol Neurophysiol. 2015;6(5):320. doi: 10.4172/2155-9562.1000320.

2. Bhargava A, Banakar BF, Pujar GS, Khichar S. A study of Guillain-Barre syndrome with reference to cranial neuropathy and its prognostic implication. J Neurosci Rural Pract. 2014;5(Suppl 1):S43-7. doi: 10.4103/0976-3147.145200.

3. Loffel NB, Rossi LN, Mumenthaler M, Lutschg J, Ludin HP. The Landry-Guillain-barre syndrome. Complications, prognosis and natural history in 123 cases. J Neurol Sci. 1977;33(12):71-9.

4. Dhadke SV, Dhadke VN, Bangar SS, Korade MB. Clinical profile of Guillain Barre syndrome. J Assoc Physicians India. 2013;61(3):168-72.

5. van Koningsveld R, Steyerberg EW, Hughes RA, Swan AV, van

Table 1. Motor Nerve Conduction Study

\begin{tabular}{lcccccc}
\hline \multirow{2}{*}{ Nerve } & \multicolumn{2}{c}{ Latency $(\mathbf{m s})$} & \multicolumn{2}{c}{ Amplitude $($ micro V) } & \multicolumn{2}{c}{ Conduction Velocity $(\mathbf{m} / \mathbf{s})$} \\
\cline { 2 - 7 } & Right & Left & Right & Left & Right & Left \\
\hline Median & 7.8 & 10.4 & 2.7 & 3.2 & 38 & 37 \\
Ulnar & 6.2 & 4.8 & 3.6 & 3.8 & 33 & 34 \\
Peroneal & 8.3 & 10.3 & 0.1 & 0.1 & 33 & 35 \\
Tibial & 7.8 & 7.4 & 1.0 & 1.7 & 40 & 45 \\
\hline
\end{tabular}

Table 2. Sensory Nerve Conduction Study

\begin{tabular}{lcccccc}
\hline \multirow{2}{*}{ Nerve } & \multicolumn{2}{c}{ Latency $(\mathbf{m s})$} & \multicolumn{2}{c}{ Amplitude $($ micro V) } & \multicolumn{2}{c}{ Conduction Velocity $(\mathbf{m} / \mathbf{s})$} \\
\cline { 2 - 7 } & Right & Left & Right & Left & Right & Left \\
\hline Median & absent & absent & absent & absent & absent & absent \\
Ulnar & absent & absent & absent & absent & absent & absent \\
Sural & 3.0 & 3.0 & 10 & 10 & 55.0 & 53.0 \\
\hline
\end{tabular}


Doorn PA, Jacobs BC. A clinical prognostic scoring system for Guillain-Barre syndrome. Lancet Neurol. 2007;6(7):589-94. doi: 10.1016/s1474-4422(07)70130-8.

6. Verma R, Chaudhari TS, Giri P. Unilateral facial palsy in Guillain-Barre syndrome (GBS): a rare occurrence. BMJ Case Rep. 2012;2012. doi: 10.1136/bcr-2012-007077.

7. St Louis EK, Jacobson DM. Unilateral third nerve palsy caused by Guillain-Barre Syndrome. Neurocrit Care. 2004;1(4):4614. doi: 10.1385/ncc:1:4:461
8. Burina A, Sinanovic O, Smajlovic D, Vidovic M. Bilateral oculomotor nerve palsy in Guillain-Barre syndrome. Med Arh. 2008;62(2):119-20

9. Ropper AH. Unusual clinical variants and signs in GuillainBarre syndrome. Arch Neurol. 1986;43(11):1150-2.

10. Imam YZ, Deleu D. Isolated bilateral ptosis as an early sign of guillain-barre syndrome. Case Rep Neurol Med. 2013:2013:178291. doi: 10.1155/2013/178291. 